\title{
ПРОБЛЕМЫ И ПЕРСПЕКТИВЫ ЭКОНОМИЧЕСКОГО РАЗВИТИЯ РЕГИОНАЛЬНОГО МОРЕХОЗЯЙСТВЕННОГО КОМПЛЕКСА АРКТИЧЕСКОЙ ЗОНЫ РОССИЙСКОЙ ФЕДЕРАЦИИ
}

\section{PROBLEMS AND PROSPECTS OF ECONOMIC DEVELOPMENT OF THE REGIONAL MARINE ECONOMIC COMPLEX OF THE ARCTIC ZONE OF THE RUSSIAN FEDERATION}

S. Belov

Summary. The topic of studying the actual problems and prospects of economic development of the regional marine economic complex related to the Arctic zone of the Russian Federation, touched upon in this article, is characterized by high practical interest. There is an objective need for its comprehensive study in connection with the current geopolitical situation in the world. The article deals with the issues based on the analysis of the existing difficulties faced by the marine economic complex of the Arctic at the present stage of its functioning. Attention is drawn to the existing potential of the spatial resources of the Arctic zone of Russia and the prospects of its impact on the further economic development of both the territory under consideration and the country as a whole are evaluated. In addition, the main directions of the Russian Federation's policy on realizing the potential of the Arctic marine economic complex and their focus on ensuring the profitability of the country's economy, as well as on fruitful international cooperation with foreign countries are outlined.

Keywords: Arctic zone, Northern Sea Route, marine economic complex, development problems, economic potential, development prospects.

\author{
Белов Сергей Валентинович \\ Aсnирант, ФГБУН ФИЦ Комплексного Изучения \\ Арктики имени академика Н.П. Лаверова Уральского \\ Отделения Российской Академии Наук \\ belov.sergeiy@gmail.com
}

Аннотация. Затронутая в настоящей статье тема изучения актуальных проблем и перспектив экономического развития регионального морехозяйственного комплекса, имеющего отношение к Арктической зоне Российской Федерации, характеризуется высоким практическим интересом. Имеется объективная потребность в ее всестороннем исследовании В связи со сложившейся геополитической ситуацией в мире. В статье рассматриваются вопросы, базирующиеся на анализе существующих трудностей, с которыми сталкивается морехозяйственный комплекс Арктики на современном этапе своего функционирования. Обращено внимание на существующий потенциал пространственных ресурсов Арктической зоны России и оценены перспективы его влияния на дальнейшее экономическое развитие как рассматриваемой территории, так и страны в целом. Кроме того, обозначены основные направления политики Российской Федерации по реализации потенциала морехозяйственного комплекса Арктики и их нацеленность на обеспечение прибыльности экономики страны, а также на плодотворное международное сотрудничество с зарубежными странами.

Ключевые слова: Арктическая зона, Северный морской путь, морехозяйственный комплекс, проблемы развития, экономический потенциал, перспективы развития.
A рктическая зона Российской Федерации занимает площадь более 4 миллионов квадратных километров и характеризуется значительной протяженностью границ по всему побережью Северного Ледовитого океана. Несмотря на невысокий уровень народонаселения, численность которого составляет всего 2,5 миллиона человек [6], Российская Арктика представляет собой уникальный регион и наделена целым спектром особенностей, привлекающих пристальное внимание с точки зрения возрастающего с каждым днем природного, транспортно-логистического и экономико-географического потенциала. Именно Арктический регион структурирует прочную базу для обеспечения продуктивного международного сотрудничества России со странами и территориями Северной Пацифики, которые включают в себя штат Аляску Соединенных Штатов
Америки, тихоокеанское побережье Канады, а также Японию. Богатейшие природные и геологические возможности региона Арктики выступают в качестве объекта всестороннего анализа и подробной оценки в мировом научном и практическом сообществе. Ученые из различных стран мира исследуют не только морские ресурсы данного региона и ископаемые недр Земли, но также систему транспортных коммуникаций, получившую название Северный морской путь. Он является ключевым транспортным коридором, посредством которого выполняется перемещение грузов в Арктическом регионе России, и включает, помимо водного пространства акватории Северного Ледовитого океана, обширную территорию суши с расположенными на ней крупными реками: Северная Двина, Печора, Обь, Енисей, Лена, Яна, Индигирка, Колыма. 
Начавшееся в 20-е годы XX века освоение Арктической зоны было ознаменовано открытием Чибьюского нефтяного месторождения промышленного назначения на территории современной республики Коми. Во второй половине прошлого века продолжилось активное развитие региона, которое сопровождалось реализацией задач народно-хозяйственного становления Арктики, обеспечения судоходства с использованием Северного морского пути от Белого моря до Берингова пролива, создания городов и планомерного их заселения. Все это привело к тому, что к 2021 году промышленный комплекс Арктической зоны Российской Федерации приобрел существенную экономическую роль, обеспечивая до 10\% ВВП страны и создавая более $20 \%$ от общего объема российского экспорта [6].

Необходимо отметить, что геополитическая ситуация современного мира претерпевает существенные изменения в последние десятилетия, которые преимущественно связаны с упрочнением на международном атласе позиций Арктического региона и его усиливающимся влиянием на макроэкономические процессы, происходящие в мире. Более того, в настоящее время можно констатировать наличие прогрессирующего противостояния между Россией и странами Запада, входящими в состав НАТО, которые прикладывают значительные усилия по наращиванию своего присутствия в Арктике. Прежде всего, это касается военной, политической и экономической активности США. С другой стороны, Китай также проявляет повышенный стратегический интерес к арктическим ресурсам, что сопровождается формированием мощного ледокольного флота для создания возможностей применения военно-морской силы с целью завоевания и удержания экономически прочных позиций на мировой арене [2].

Политика российского государства, связанная с усиленной реализацией программы импортозамещения, активным финансированием национальных разработок в области стимулирования технического прогресса, развития технологий и создания оборудования, выступила как следствие серьезного вызова западных стран в адрес России. Она послужила адекватным ответом нашей страны на ряд секторальных санкций, введенных Европейским Сообществом, США, Канадой и некоторыми другими мировыми державами. Поэтому перспективы развития региона Российской Арктики сегодня рассматриваются со всей серьезностью как стратегический ресурс, потенциал и возможности которого могут быть использованы для снижения зависимости российской нефтегазовой отрасли и экономики в целом от влияния зарубежных стран [4].

Активная, нацеленная на устойчивый прогресс позиция России в направлении развития Арктического региона получила свое отражение в официальном нормативно-правовом акте «Стратегия развития Арктической зоны Российской Федерации и обеспечения национальной безопасности на период до 2035 года», утвержденной Указом Президента РФ от 26.10.2020 № 645 [1]. В качестве одного из приоритетных направлений Стратегии обозначено создание и развитие предприятий морехозяйственного комплекса Арктической зоны, в том числе функционирующих с целью осуществления ремонта, снабжения и бункеровки судов. Также внимание уделено развитию береговых баз с целью создания в акватории Северного морского пути условий для судоходства и реализации других морехозяйственных проектов. Кроме того, в документе отмечается приоритетность развития рыбохозяйственного комплекса в целях сохранения и преумножения его ресурсного потенциала, подчеркивается значимость технического перевооружения и модернизации действующих рыбохозяйственных и морехозяйственных предприятий. Внимание уделено потребности в строительстве новых судов, ввода в эксплуатацию новейших производственных мощностей по глубокой переработке морских биологических ресурсов, отвечающих последнему слову техники и самым современным организационным принципам.

В число приоритетных направлений Стратегии также включено создание и организация бесперебойного функционирования Центра строительства крупнотоннажных морских сооружений, деятельность которого планируется связать с производством, хранением и отгрузкой сжиженного природного газа в соответствии с энергетическими потребностями России. В Стратегии предусмотрены мероприятия, связанные с комплексным развитием морского порта Мурманск, который является незамерзающим арктическим транспортным узлом, основным преимуществом которого является мультимодальность. На его территории предполагается разместить новейшие терминалы и перевалочные комплексы, которые будут обеспечивать эффективную и бесперебойную работу, независимо от сезонности.

Современная российская экономика динамична, подвижна, и ее переход на очередной этап развития предполагает, что руководству страны необходимо признавать морехозяйственный комплекс в качестве стратегического ресурса арктического территориального пространства. Это ставит «ребром» вопрос о рациональном и наиболее оптимальном использовании имеющегося в его распоряжении потенциала. Данному направлению развития должно способствовать совершенствование организации всех видов социально-экономической деятельности региона, в том числе и осуществление вложений в направлении развития человеческого капитала, сферы услуг, повышение качества эксплуатации транспортных 
систем и добычи природных ресурсов при условии соблюдения мер экологической безопасности.

Перспективы развития морехозяйственного комплекса России связаны с политическим и стратегическим аспектами российской экономики, нацеленной на максимизацию доходов от всех видов деятельности. В связи с этим предполагается, что оценка и реализация потенциальных возможностей экономического развития Арктической зоны РФ будет базироваться на следующих основных принципах:

- глобальный характер преобразований. Поскольку российский Арктический регион представляет собой лишь часть мировой Арктики, все происходящие на его территории процессы должны принимать во внимание мировые тенденции развития, базирующиеся на международных принципах взаимовыгодного сотрудничества стран в соответствии с действующими нормами законодательства государств - участников региона;

- суверенность Арктической зоны. Регион российской Арктики представляет собой важнейшую составляющую природной и социально-экономической системы страны, в связи с этим реализация региональных перспектив и предпринимаемые меры по их регулированию должны иметь в качестве стратегической цели защиту национальных экономических интересов и суверенитета России.

Морехозяйственный комплекс Арктической зоны России на сегодняшний день включает в себя несколько направлений деятельности, а именно: рыбохозяйственное, транспортное, морское и военно-морское направления, а также вспомогательную деятельность инфраструктурных предприятий, расположенных на прибрежных территориях. Так, рыбохозяйственное направление предполагает взаимосвязанное функционирование предприятий, обеспечивающих выполнение научно-исследовательских работ, проведение разведки и добычи природных биоресурсов, их последующую транспортировку, переработку и хранение. Здесь особое место занимает рыбная отрасль, поскольку современный Северный рыбохозяйственный бассейн обеспечивает более $12 \%$ от общего улова в России [6]. В качестве перспектив развития данного направления деятельности морехозяйственного комплекса Арктической зоны России можно выделить строительство новых перерабатывающих предприятий, а также увеличение количества судов, входящих в состав рыболовного флота, в соответствии с подписанными контрактами. По предварительным оценкам ожидается, что для этого потребуется привлечь в отрасль около 130 млрд. рублей в качестве инвестиционных вложений, что позволит к 2023 году повысить показатели вылова рыбопродуктов на 1 млн. тонн в год [5].
Неоспоримым остается факт, что такие виды сырья и топлива, как нефть, газ, жидкие углеводороды на сегодняшний день не имеют природных или искусственных аналогов, поэтому не могут быть замещены в полной мере каким-либо другим альтернативным источником. В связи с этим формирование экономических потребностей страны в данных ресурсах напрямую зависит от геологического и природного потенциала российского Арктического региона, а также уровня развития морехозяйственного комплекса, обеспечивающего доступ к природным кладовым посредством использования Северного морского пути. Здесь немаловажная роль отведена функционирующим производственным комплексам, качеству и степени развития инфраструктуры региона, степени оснащенности газо- и нефтепроводов, транспортным коммуникациям и телекоммуникациям. Особое значение приобретает наличие незамерзающих морских портов, располагающих открытым выходом в Мировой океан (например, таких как Мурманск), а также трансграничных транспортных коридоров, которые позволяют Арктическому региону России принимать непосредственное участие в национальных и международных экономических процессах.

Очевидно, что Россия, обладая доступом к арктическим маршрутам и контролируя их транспортные потоки, получает возможность влияния на мировую торговлю. Основное преимущество Северного морского пути и связанные с ним перспективы заключаются в том, что стоимость перевозки ресурсов внутри Евразии посредством данного международного маршрута позволяет получить экономию транспортных затрат в размере $40 \%$. В связи с этим высокое стратегическое значение приобретают возможности России, обладающей прямым выходом в Мировой Океан. Однако низкие темпы развития береговой инфраструктуры, расположенной вдоль транспортных потоков Северного морского пути выступают в качестве основных сдерживающих факторов совершенствования существующих и создания новых транспортных маршрутов. Здесь одним из перспективных направлений выбрано решение задачи соединения инфраструктуры морских портов и транспортных коммуникаций, расположенных на материке, в единую логистическую комплексную систему. Эти перспективы приобретают особое значение в условиях очагового характера освоения российской Арктики, при которых промышленные центры характеризуются удаленностью от основных транспортных магистралей. В данном случае существует острая необходимость построения разветвленной сети автомобильных и железных дорог на суше, связанных в единую систему с грузовыми потоками Северного морского пути для совершенствования процесса добычи и перевозки полезных ископаемых, а также с целью поддержания высокого уровня жизнеобеспечения населения, проживающего в регионе [3]. 
Традиционно основой морехозяйственного комплекса Арктики считается флот, техническая эксплуатация которого должна обеспечиваться устойчивой, развитой и конкурентоспособной инфраструктурой. Наиболее значимой составляющей сервисной инфраструктуры является система судоремонтных предприятий, относящихся к отрасли машиностроения и характеризующиеся мелкосерийным, а зачастую и единичным типом производства. Данная система на текущий момент времени имеет объективную потребность в реализации собственного промышленного потенциала, в инновационном развитии с целью повышения конкурентоспособности судоремонтных услуг и обеспечения дальнейшего устойчивого экономического развития региона и страны в целом.

Несмотря на особую важность и значимую роль морехозяйственного комплекса Арктического региона в экономике России, на сегодняшний день данное направление все еще остается проблемным. В первую очередь, это связано с неоднородностью и напряженностью социально-экономической ситуации в регионе. Политика региона в данном векторе базируется, в большей части, на научных основах, которые не способствуют тщательной проработке социально-экономических аспектов и не способны в полной мере сформулировать собственную активную позицию региона по отстаиванию интересов немногочисленного народонаселения Арктической зоны Российской федерации.

Роль российской Арктики и, в частности, ее морехозяйственного комплекса в национальной экономике повышается с каждым годом, при этом существующие на сегодняшний день государственные политические и правовые основы не отвечают практическим интересам и не до конца учитывают специфику развития Арктического региона. Поэтому важнейшим сдерживающим фактором, препятствующим реализации арктического потенциала России в полной мере, выступает отсутствие системной и научно-дифференцированной политики государства в отношении Арктического региона, поддерживаемой и реализуемой на федеральном уровне.

При изучении проблем и перспектив морехозяйственного комплекса российской Арктики нельзя не принимать во внимание и такую неоднозначную и специфичную проблему, как глобальное изменение климата. В случае сохранения тенденций масштабного потепления и сдвигов климатических поясов, на всем протяжении Северного морского пути будут созданы объективные предпосылки для улучшения условия судоходства и морехозяйствования. С другой стороны, уже в обозримом будущем будут усиливаться процессы таяния зон вечной мерзлоты и ледников, что, в свою очередь, приведет к обострению проблем промышленного, социального, транспортного, экономического характера, а также может привести к необратимым экологическим последствиям и созданию угрозы природной катастрофы.

Таким образом, подводя итог исследования проблем и перспектив развития морехозяйственного комплекса Арктической зоны России, можно сказать, что регион таит в себе колоссальный природный, стратегический и экономический потенциал, разработка которого возможна только при условии применения комплекса эффективных политических, социально-экономических, экологических методов. Морехозяйственный комплекс Арктики характеризуется уникальностью, его освоение и развитие должно происходить на основе гармоничного сочетания технологических аспектов и факторов природной среды, поскольку связанные с этим процессом риски достаточно высоки. Комплексная реализация перспектив экономического развития Арктической зоны страны - задача крайне сложная, однако ее успешное решение должно стать не только импульсом для инновационного развития национальной экономики, но и беспрецедентным вызовом России всему мировому сообществу.

\section{ЛИТЕРАТУРА}

1. Указ Президента Российской Федерации от 26 октября 2020 года $N 645$ «0 Стратегии развития Арктической зоны Российской Федерации и обеспечения национальной безопасности на период до 2035 года».

2. Вызовы и угрозы национальной безопасности в Российской Арктике. Научно-аналитический доклад. - Апатиты: изд. КНЦ РАН, 2017. — 53 с.

3. Проблемы и перспективы развития Северного морского пути как элемента единой Арктической транспортной системы // Аналитическое управление Аппарата Совета Федерации, 2019.- 16 c.

4. Селин В.С. Промышленный комплекс Севера после санкций // Инновации, 2015.— № 7.— С. 90-95.

5. Турчанинова Т.В., Храпов В.Е., Кибиткин А.И. Системный подход к пространственной организации морехозяйственной деятельности прибрежного региона // Экономика в промышленности, 2015.—№ 1.- С. 25-33.

6. Федеральная служба государственной статистики. — Режим доступа: https://rosstat.gov.ru/

(с Белов Сергей Валентинович ( belov.sergeiy@gmail.com ).

Журнал «Современная наука: актуальные проблемы теории и практики» 